\title{
ALÉM DAS ÁGUAS, A DISCUSSÃO NO NORDESTE DO RIO SÃO FRANCISCO \\ Luiz Cruz Lima
}

Resumo: Este trabalho apresenta uma síntese da história do Projeto de transposição de águas do Rio São Francisco para as bacias do Nordeste Setentrional. Essas obras objetivam assegurar as reservas de água nos períodos secos, para os homens e para os animais. Além de indicar o caminho dessa transposição, o texto relaciona os impactos sociais das mudanças ambientais. No fim, trata da nova geografia das águas, adotando o modelo de ação humana sobre a natureza, proposto por Milton SANTOS.

Palavras-chave: Transposição das águas; Nordeste brasileiro; Impactos sociais; Seca

\section{Introdução}

É natural que na vida democrática as propostas de largo alcance provoquem amplas discussões, dúvidas, posições opostas e radicais, como também adesões conscientes e outras eivadas de emotividades, de oportunismos e interesses capciosos. Em recente fase de nossa história não se abria oportunidade para debates, para oposições, definindo-se como o tempo da imposição do poder superior. 0 consenso era obrigatório como falta de senso. Neste início de século entramos num ciclo de retomada do debate, do aporte dos contraditórios, fonte da criação e do aperfeiçoamento das idéias.

Quando o objeto exposto é de tradição histórica, o tempo remoto se mescla com o cotidiano, mas envolto nas modalidades do tempo de ontem quando 0 objeto foi apresentado pela primeira vez, arrastado para o tempo de hoje, com as novidades das inovações técnicas e organizacionais. Não esqueçamos que vivemos em período dominado pelo conhecimento técnicocientífico informacional (SANTOS, 1994), em que as intensas relações da sociedade com a natureza se definem como conquista do homem, nem sempre como domador, mas também como conhecedor dos mistérios naturais e sabendo tirar proveito deles, no momento oportuno. Veremos, no final, como essas possibilidades foram propostas por um teórico da ciência geográfica. Isso está posto com o Projeto de Integração da bacia do Rio São Francisco com as do Nordeste Setentrional, envolvendo os Estados Ceará, Paraíba, Rio Grande do Norte e Pernambuco. Este projeto, debatido em diferentes temporalidades, reapareceu renovado para atender velhos problemas regionais.

\section{História da transposição do Rio São Francisco}

Esse é tema recorrente e emoldurado por três séculos.
BEZERRA (2002) registra que em tempos idos o padre carmelita João de Santa Rosa "elaborou um documento nesse sentido e enviou-o ao monarca D. João VI, do Reino Unido de Portugal, Algarve e Brasil. Este, às vésperas de deixar o Brasil (abril de 1821), teria recomendado a construção da obra a seu filho, o Imperador D. Pedro I, que ordenou ao sr. Costa Barros, presidente da Província do Ceará, que diligenciasse no sentido de verificar 'a possibilidade e vantagens de tal empreendimento'. Os estudos nesse sentido caíram no esquecimento por causa dos episódios que marcaram a Confederação do Equador em 1824, movimento separatista ocorrido em várias províncias nordestinas". Foi uma proposta que ficou no esquecimento.

A idéia oficial nasce na ombreira do Império, no início da segunda metade do século XIX com a famosa Comissão Científica de Exploração, chefiada pelo engenheiro e físico brasileiro Guilherme Schuch de Capanema (Barão de Capanema), que propôs a construção de açudes e a integração do Rio São Francisco com os rios do Nordeste Setentrional. Era na época uma proposta ousada, mas indicativa para minimizar a tragédia que ocorreria no último quartel do século, com a morte de quase dois milhões de habitantes do Nordeste. Como foi ocorrer, depois da tragédia ressoam tardiamente as medidas para "solucionar" o problema. Em 1884 resolve-se construir o primeiro açude no Ceará, o de Quixadá. Transcorreram vinte e dois anos para inaugurar o Açude, quando foi institucionalizada a Inspetoria Federal de Obras Contra a Seca (IFOCS). Na ditadura de Getúlio Vargas, a IFOCS passa a ser chamada Departamento Nacional de Obras Contra as Secas (DNOCS). BEZERRA (2002) lembra que "estudos topográficos iniciais foram realizados em 1912 pela antiga IFOCS. Em 1913, o projeto foi considerado inviável e comdenado pelo seu primeiro diretor, Miguel Arrojado Lisboa" (p. 113), 
talvez pela inviabilidade técnica.

Em 1980, no âmbito do Departamento Nacional de Obras de Saneamento (DNOS), dentro do Plano de irrigação do semiárido, novamente o Rio São Francisco volta ao palco do planejamento, como fonte complementar de águas para os rios nordestinos com uma captação de $42,4 \mathrm{~m}^{3} / \mathrm{s}$ de sua vazão.

Em 2004 retorna com mais força a discussão em torno do Projeto da Transposição das águas do Rio São Francisco. Então, o volume a ser captado seria de mais $50 \%$ ao proposto em 1980 , o que, depois de muita crítica e alarde, chega a "uma cuia de água", no dizer do Presidente Lula, de $26 \mathrm{~m}^{3} / \mathrm{s}$, para molhar parte do chão da Paraíba, Rio Grande do Norte, Ceará e Pernambuco, onde, dizem as fontes oficiais (BRASIL, 2005), seriam beneficiados doze milhões de nordestinos. É evidente que esse filete de água apenas resguardará a permanência de águas em alguns açudes, num processo de sinergia hídrica, no dizer dos técnicos, e atenderia as necessidades de sobrevivência nos longos corredores de dez quilômetros de largura por onde passará o canal nos estados acima mencionados.

\section{Benefícios e mal-estar}

Documentos, reuniões, debates na mídia, envolvendo técnicos, políticos, intelectuais e o povo em geral, têm contribuído para formar uma platéia para aplausos ou vaias às propostas de governo (MAGALHÃES, 2005; SBPC, 2004). Em sua primeira parte, o Relatório de Impacto Ambiental, RIMA - realizado pelas empresas AGRAR-MEIO AMBIENTE e ECOLOGY BRASIL, contratadas pelo Governo Federal (BRASIL, 2004b) - diz: "Para beneficiar a região mais seca do País, a captação de água do rio São Francisco será de cerca de $3,5 \%$ da sua vazão disponível". Em outras palavras, dos $1850 \mathrm{~m}^{3} / \mathrm{s}$ de água do rio São Francisco, $63,5 \mathrm{~m}^{3} / \mathrm{s}$ serão retirados. Desse volume, $42,4 \mathrm{~m}^{3} / \mathrm{s}$ serão destinados às bacias do Jaguaribe, Apodi, Piranhas-Açu e Paraíba, e $21,1 \mathrm{~m}^{3} / \mathrm{s}$, ao Estado de Pernambuco que compartilha a bacia do São Francisco. Diante das inúmeras críticas, demonstração de cálculos e preocupações com os múltiplos usos, ainda, previstos pela demanda da bacia sanfranciscana, além de outorgas já concedidas, o governo restringe a captação para $26,0 \mathrm{~m}^{3} / \mathrm{s}$, o que não acabou com as críticas.

A captação desse volume de água será feita em dois pontos, direcionando dois eixos de integração, conforme diz o mencionado Relatório: "Dois sistemas independentes, denominados EIXO NORTE e EIXO LESTE, captarão água no rio São Francisco entre as barragens de Sobradinho e Itaparica, no Estado de Pernambuco" (BRASIL, 2004a). Compostos de canais, estações de bombeamento, pequenos reservatórios e usinas hidrelétricas para auto-suprimento, esses sistemas atenderão às necessidades de abastecimento de municípios do Semi-Árido, do Agreste Pernambucano e da Região Metropolitana de Fortaleza. As bacias hidrográficas beneficiadas são as do rio Jaguaribe $(\mathrm{CE})$, do rio Piranhas-Açu (PB e RN), do rio Apodi (RN), do rio Paraíba (PB), dos rios Moxotó, Terra Nova e Brígida (PE).

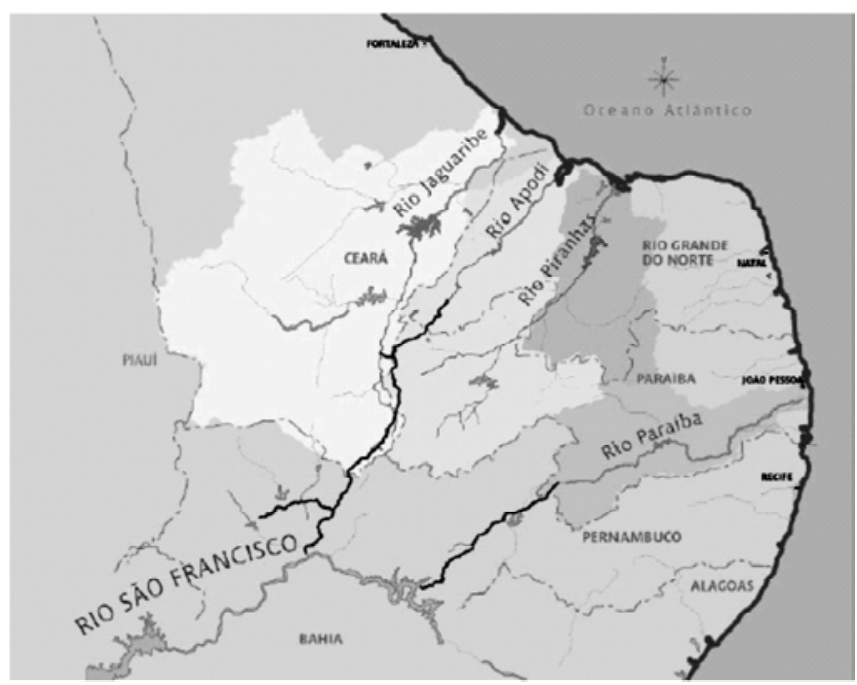

Figura 1 Bacias Receptoras do Nordeste Setentrional. Fonte: BRASIL, (2004a).

Por certo as obras, além dos canais, serão de grande monta, provocando muitos impactos no ambiente e especialmente na vida das coletividades. Selecionamos para discussão dezoito impactos de caráter social, dentre quarenta e quatro relacionados pelo Estudo de Impacto Ambiental (BRASIL, 2004b) e expostos no Relatório de Impacto Ambiental, no intuito de abri-los ao debate. Desses, onze são de caráter benéfico, mas de repercussão na vida social.

\section{Aumento da oferta e da garantia hídrica. Esse é o} principal objetivo do Projeto, porquanto se planeja no sentido de garantir a disponibilidade, no decorrer dos anos, de água suficiente para o consumo humano e animal, sem descartar a continuidade dos demais usos, como irrigação empresarial, hoje uma das atividades de elevada expressão em parte do Nordeste, ressaltando o vale do Rio Jaguaribe, no Ceará. O Relatório indica, como uma medida básica, a gestão dos recursos hídricos. Ressaltamos que o Estado do Ceará é líder nessa ação, com experiência de anos e implantação de um importante canal de integração de bacia, além do funcionamento dos comitês de bacias, como se pode verificar no sítio www.srh.ce.gov.br. Os demais estados estão, com base nas experiências do Ceará, 
instalando sua estrutura de recursos hídricos nesse sentido.

2. Geração de empregos e renda durante a implantação. É natural que implantação de grandes obras atraia um elevado contingente de trabalhadores. É necessário que haja medidas mitigadoras para o período posterior à conclusão das obras, visto que é sabido pelas experiências de construção de grandes obras, surgirem alojamentos, formação de agrupamentos humanos que se direcionam a formar embriões urbanos, muitas vezes, sem as condições humanas obrigatórias. Há uma previsão de 5000 empregos diretos, o que implica, no mínimo, num contingente de 10 mil pessoas, mesmo com a contratação de mão-de-obra local.

3. Dinamização da economia regional. Cerca de 14 canteiros de obras estão previstos: Cabrobó, Salgueiro, Terra Nova, Parnamirim, Jati, Cajazeiras, Triunfo, Uiraúna, Custódia, Sertânia, Mauriti, Baixio, Floresta e Petrolândia. Essa é uma demonstração da abrangência territorial, somente na fase de implantação das obras. Na teoria geográfica, sabemos que a instalação de um objeto espacial gera múltiplas relações, nem sempre previsíveis, quer de volume, quer de natureza dos fluxos. Essa constatação nos leva a indagar sobre as possíveis mudanças de comportamento das atividades econômicas e do movimento demográfico. Dentre as medidas propostas, uma de fundamental importância a ser monitorada, envolvendo também os governos locais: implementar medidas de gestão junto aos governos estaduais beneficiados, procurando atender aos subprojetos integráveis previstos nas regiões receptoras.

4. Aumento da oferta de água para abastecimento urbano. Esta é a base do grande Projeto de Transposição. Como os governos estaduais, especialmente do Ceará, já desenvolvem ações e projetos nesse sentido, o Projeto de Integração se apresenta como regulador da oferta, pois manteria as bacias receptoras em nível de certeza em atender as demandas previstas. Dentro dessa perspectiva, medidas são postas como combate ao desperdício de água, educação da população para 0 uso consciente e adequação do que seja utilizado às margens dos canais.

5. Abastecimento de água das populações rurais. Nessa condição, prevê-se a instalação de chafarizes públicos em cerca de 400 localidades urbanas, todas inseridas na Área Diretamente Afetada (ADA), beneficiando cerca de 70 mil pessoas. Assim, deseja o Projeto criar meios de educação para promover uso adequado dos recursos hídricos, então disponíveis, além de viabilizar condições concretas para o abastecimento domiciliar.
6. Redução da exposição da população a situações emergenciais de seca. Este objetivo tem relação direta com 0 que se propõe no Projeto, com o fim de eliminar diferentes problemas, em função da pouca oferta de água: desemprego no meio rural, escassez de alimentos, baixa produtividade no campo, dizimação dos rebanhos, queda no nível socioeconômico e êxodo da população local. Seriam beneficiadas 340 mil pessoas, com ênfase aos que estão situados na bacia do Piranhas-Açu (39\%) e na bacia do Jaguaribe (29\%).

7. Dinamização da atividade pecuária e incorporação de novas áreas ao processo produtivo. Visando integrar pequenos produtores no processo de produção agrícola, projeta-se a recuperação de áreas abandonadas, como, por exemplo, 0 projeto de irrigação de Poço da Cruz, em Ibimirim (PE); a inserção de áreas ao longo dos canais a serem construídos e dos rios receptores, denominadas de irrigação difusa; e, finalmente, a inserção de outras áreas que apresentam potencial para 0 desenvolvimento agrícola na região semi-árida e que não estão produzindo por falta d'água. Além de atuar no Programa de Fornecimento de Água e Apoio Técnico para Pequenas Atividades de Irrigação ao Longo dos Canais para as Comunidades Agrícolas, mantêm-se as ações de educação ambiental direcionada ao uso racional da água e à melhoria dos solos agrícolas.

8. Melhoria da qualidade da água nas bacias receptoras. Uma das grandes preocupações nas transposições é manter a qualidade da água transportada. Sabe-se que dos locais de recepção (Ilha de Assunção e Reservatório de Itaparica) saem água de melhor qualidade que as das bacias receptoras, o que muito contribuirá para melhorar a produtividade das atividades aplicadas, além de oferecer condições favoráveis à saúde do consumidor.

\section{Diminuição do êxodo rural e da emigração da região.}

Por estar atendendo as necessidades de água, há previsão de que 400 mil pessoas sejam aliviadas das agruras da falta d'água. Dentre os usos possíveis para as populações em torno do canal, incentiva-se a piscicultura para atender as necessidades de alimentação local. Isto equivale a contribuir para reduzir o êxodo rural, com alívio para as grandes cidades. Em termos imediatos, as empresas de construção das obras do Projeto serão estimuladas a contratar mão-de-obra local.

10. Redução da exposição da população a doenças e óbitos. Há uma permanente incidência de doenças no semi-árido, muitas identificadas pela extrema pobreza, mas muitas ligadas à falta de água, bem fundamental para a saúde e a higiene. Não há 
como discordar das assertivas expostas no RIMA sobre o declínio dos índices de mortalidade quando o Projeto estiver operando plenamente, em 2025. Há uma estimativa de 53.000 casos de internações em face da carência de água na região a ser beneficiada. Paralelamente à execução das obras, o governo oferece quatro importantes projetos direcionados a esse fato: Programa de Implantação de Infra-Estrutura de Abastecimento de Água às Populações ao Longo dos Canais; Programa de Educação Ambiental; Programa de Monitoramento de Vetores e Hospedeiros de Doenças e Programa de Controle de Saúde Pública.

11. Redução da pressão sobre a infra-estrutura de saúde. Apesar da demanda por equipamento de saúde se fazer sempre, especialmente nas localidades mais carentes de emprego e renda, por certo, que melhores condições de vida, oferecidas pela oferta de recursos hídricos, minimizará a pressão sobre esses equipamentos. Mas isso não dispensa a luta contra esses vetores de doenças. Daí a proposta do Programa de Monitoramento de Vetores e Hospedeiros de Doenças e de Controle de Saúde Pública.

Paralelamente a estes impactos favoráveis à melhor condição de vida, com ofertas de água, trabalho temporário e outras medidas positivas, o Projeto propiciará um conjunto de fatos que poderão trazer problemas para a população atingida, com ênfase para os que se localizam na Área diretamente afetada (ADA), correspondente a $5 \mathrm{~km}$ ao longo do canal. É também, visualizada a repercussão negativa para as comunidades tradicionais, não apenas para sua vida material, mas também para sua cultura. Isso se estende às cidades ou povoados que terão agregação de mais habitantes ou elevada a demanda por seus parcos serviços. Vejamos agora os impactos negativos.

12. Perda temporária de empregos e renda por efeito das desapropriações. Em fases de rupturas de um sistema, sempre se espera que ocorra mudança brusca no cotidiano. Isso é presente em empregos e renda, quando houver ações como desapropriação de terras e início das obras, como prevê o estudo: estima-se a perda de 2300 empregos diretos, principalmente nas zonas rurais de Salgueiro, São José das Piranhas, Verdejante, Baixio e Santa Helena. O segundo momento de queda no emprego deverá ocorrer ao final das obras. Há casos em que as expectativas geram mobilidade espacial de trabalhadores em busca de emprego e não encontram ocupações, gerando desemprego onde não ocorria antes. Os estudos apresentam indicativos para algumas medidas mitigadoras desses impactos: desenvolver ações voltadas para as famílias desapropriadas e priorizar a contratação de mão-de-obra local no início das obras, para facilitar a reintegração social dos dispensados ao final delas.

13. Introdução de tensões e riscos sociais durante a construção. Para quem não participa do mercado de trabalho, a expectativa ante aos Programas desse tipo sempre se eleva. Ademais, outras pessoas chegarão em busca de trabalho, gerando um superávit da oferta de mão-de-obra, o que amplia o índice de desemprego. Daí, medidas propostas no Estudo devem ser levadas a sério, tais como: divulgar as oportunidades de emprego entre os moradores locais; recomendar às empreiteiras que contratem, ao máximo, mão-de-obra local durante a construção; discutir e divulgar de forma ampla os critérios para aquisição de terras e recolocação de pessoas. Além dessas tensões, foram contabilizadas como possível impacto acidentes com veículos em circulação, cuja medida cautelar mais lógica é ampliar a sinalização nas vias de acesso e estradas locais, de modo a evitar acidentes com veículos.

\section{Ruptura de relações sócio-comunitárias durante a}

fase de obra. Intervenções de grande vulto, com ampliação do efetivo demográfico (grandes barragens, construção de cidades planejadas, etc) sempre geram conflitos com as comunidades residentes próximas às obras, gerando sérios prejuízos sócioculturais e econômicos, representados estes por aquisição de imóveis a preços baixos, expulsando pessoas da comunidade. Para deter essas ações perniciosas, o Estudo propõe realizar uma ampla divulgação e discussão dos critérios de compra de terras e de realocação das pessoas.

15. Possibilidade de interferências com populações indígenas. $O$ desrespeito às comunidades indígenas é fato histórico no Brasil, mesmo nos anos mais recentes. É preocupante quando a engenharia opera obras que atraem muitos trabalhadores, próximas a povoados dos índios, comumente não afeitos ao ditames da sociedade de consumo e às perversões do sistema moderno. Duas comunidades estão mais sujeitas a essas influências: Pipipan (aldeia Caraíba) e Truká (llha de Assunção, próxima à captação do Eixo Norte). Julgando ser o projeto de elevada importância social, o estudo apresenta como medidas cautelares aos riscos: (a) um Programa de Apoio às Comunidades Indígenas vai procurar minimizar possiveis incômodos causados pelas obras; (b) ações de compensação também deverão suprir carências reais destes grupos, diante da nova situação que se configurará; (c) divulgar intensivamente programas de saúde, com ênfase especial para doenças infecto-contagiosas e sexualmente transmissiveis; (d) orientar os técnicos e demais trabalhadores 
das obras sobre os cuidados que deverão ser tomados quando tiverem contato com as comunidades indígenas; (e) melhorar a sinalização das terras indígenas, de modo a evitar a entrada de pessoas estranhas e criar formas de comunicação direta entre os líderes das comunidades e o empreendedor.

16. Pressão sobre a infra-estrutura urbana. Elevados índices de deficiências de habitação, saneamento, equipamentos de educação e de saúde são problemas crônicos das cidades do Nordeste brasileiro. Interiorizando-se, esses índices elevam-se mais ainda, revelando a precariedade da vida urbana da região. Com a efetivação de obras do porte da Transposição, as pequenas cidades, próximas aos canteiros de obras, não oferecem condições de atender os trabalhadores, o que exige uma ação antecipada, tanto em dar preferências à mão-de-obra local (qualificando-a), como criar meios viáveis de abastecer e oferecer serviços adequados ao efetivo de trabalhadores, além de oferecer apoio aos governos municipais em foco.

\section{Risco de interferência com o Patrimônio Cultural.} Dada as dimensões das obras nos percursos definidos para a integração das bacias, com sérios riscos aos sítios arqueológicos presentes na área atingida, convém que se efetivem o que se propõe: realizar prospecção arqueológica e levantamento de áreas de interesse cultural, antes da implantação das obras civis; efetuar o salvamento de amostras representativas do patrimônio arqueológico e registrar características culturais identificadas; promover ações de educação patrimonial nos municípios diretamente afetados pelo empreendimento e treinar os trabalhadores para reconhecerem vestígios arqueológicos.

18. Interferência sobre a pesca nos açudes receptores. Esse impacto tem caráter ambiental, nos recursos bióticos, mas de importância direta na sobrevivência imediata das populações, daí incluirmos como impacto social. O RIMA relaciona de modo claro e evidente a problemática e as medidas viáveis para sua minimização: com a diminuição do volume médio dos açudes existentes, por causa das novas regras operacionais do Projeto de Integração, ocorrerá a diminuição espacial do habitat disponível para os peixes nesses açudes. Por outro lado, a ocorrência da "mistura" de espécies do rio São Francisco com espécies das bacias receptoras acarretarão, nos açudes, 0 aumento do número de espécies (maior qualidade de peixes), que competirão pelos mesmos recursos hoje existentes (alimento, ambientes adequados para reprodução, etc). 0 resultado desta situação, será a provável diminuição da biomassa (quantidade) de espécies hoje pescadas e comercializadas na região. Entretanto, novas espécies de valor comercial, como o dourado e o surubim poderão ser introduzidas, criando novas opções para a pesca.

Medidas propostas: (a) executar o Subprograma de Monitoramento da Ictiofauna, que deverá acompanhar o rearranjo das populações das espécies de peixes, com foco especial nos Açudes e (b) realizar o Programa de Apoio ao Desenvolvimento de Atividades de Piscicultura, inclusive nos açudes projetados.

\section{Uma nova geografia das águas}

Graças às inovações técnicas, a sociedade transforma a natureza em seu benefício. Essas mudanças devem ser feitas de modo criterioso, lançando mão dos requisitos técnicos e científicos hoje à disposição do homem, tanto para não criar uma natureza hostil, como para beneficiar o maior número possivel de pessoas, sem detrimento de tantas outras. Ao se tratar de questões muito complexas, dispomos de conhecimentos modernos, além das discussões políticas que são capazes de reverter a maioria dos aspectos negativos, maximizando os favoráveis à vida da maioria. Um bom caminho é seguir inicialmente o que SANTOS (1988) indicava como critérios metodológicos: "a busca da explicação das transformações passa pela compreensão dos grandes grupos de variáveis, que compõem o território, a começar pelos indicadores mais comuns a este tipo de trabalho até os mais complexos, reveladores das grandes mudanças ocorridas no período técnico-científico..." Com o que se tem apresentado nos debates, notamos, dia a dia, mais revelações, com base em aprofundamento da realidade do objeto discutido, conduzindo-se a compreender que as tomadas de decisões abertas possibilitam uma maior certeza de uso mais adequado do território em benefício dos homens. Com a vontade de atender outra parte do Nordeste que sente a rispidez das secas, sem prejudicar a outra que se habituou a utilizar a dádiva de seu manancial hídrico, sabendo que "o progresso técnico não elimina a ação da natureza", é inegável que estamos nos aproximando de uma decisão: definir um adequado modelo de ação humana, proposta por SANTOS (1988): "Quando o homem tem força para modificar os aspectos
do quadro natural, fazendo deste uma Segunda Natu-
reza mais adaptada aos seus fins; quando o homem,
prevendo as mudanças conjunturais do quadro natural,
se prepara, seja para tirar partido dessa mudança, seja
para reduzir os seus efeitos nefastos ou puramente
negativos; quando, através do conhecimento das
possibilidades de oscilações das condições naturais - 
comsideradas em relação com a atividade humana desenvolvida nesta ou naquela área - o homem imagina, elabora, codifica, impõe um sistema regulador mediante o qual os danos sociais ou individuais são objetivamente absorvidos."

Acreditamos que o Projeto em discussão se enquadra nesses modelos, dada sua complexidade e dualidade - bacia doadora e bacias receptoras - na perspectiva de converter os fenômenos naturais, respeitadas suas contingências, às necessidades humanas. Assim, o que encontramos nesse Projeto é um exemplo do trabalho multi e interdisciplinar, conjugado pela amplitude da geografia (física e humana) em benefício dos grandes problemas da sociedade. 
LIMA, L. C. (2005). Beyond the waters, the northeast discussion of São Francisco River. Revista do Departamento de Geografia, n. 17, p. 94-100.

Abstract: This work presents a synthesis of the history of the Project of Water Transposition from São Francisco River to the basins on the northern part of Northeast. Those works aim to assure water supply during the dry periods, for men and animals. Besides indicating the historical way of that transposition, the text lists the social impacts from the environmental changes. Finally, it deals with new water geography, adopting the model of the human action on nature proposed by Milton SANTOS.

Key words: Transposition of waters; Brazilian Northeast; Social impacts; Drought.

Recebido em 7 de setembro de 2005, aceito em 02 de outubro de 2005.

\section{Referências}

BEZERRA, E. (2002) O Rio São Francisco: a polêmica da transposição. Fortaleza: Série A Gráfica.

BRASIL (2005) Ministério da Integração Nacional (disponivel em www.integraçao.gov.br/saofrancisco).

(2004a) Projeto de Integração do Rio São Francisco com Bacias Hidrográficas do Nordeste Setentrional. Estudo de Impacto Ambiental, elaborado pelo AGRAR-meio ambiente e Ecology Brasil.

(2004b) Projeto de Integração do Rio São Francisco com Bacias Hidrográficas do Nordeste Setentrional. Relatório de Impacto Ambiental , elaborado pelo AGRAR meio ambiente e Ecology Brasil.

MAGALHÃES, P.C. (2005) A Transposição das Águas do Rio São
Francisco in Ciência Hoje. Instituto Ciência Hoje (SBPC), n²17, v.37, julho, p. 40-52.

SANTOS, M. (1988) Metamorfoses do espaço habitado. São Paulo: HUCITEC, 1988.

(1994) Técnica, Espaço, Tempo; globalização e meio técnico-científico informacional. São Paulo: HUCITEC.

SBPC; CEPEN (2004) Encontro Internacional sobre Transferência de Águas entre Grandes Bacias Hidrográficas. Sociedade Brasileira para o Progresso da Ciência e Centro de Estudos e Projetos do Nordeste. Decorrente do workshop A Transposição de Águas do Rio São Francisco, realizado em Recife. Outubro de 2004.

SUASSUNA, J. (s/d) Textos variados. Fundação Joaquim Nabuco (disponível em www.fundaj.gov.br). 